\title{
Neonatal Adverse Event
}

National Cancer Institute

\section{Source}

National Cancer Institute. Neonatal Adverse Event. NCI Thesaurus. Code C154913.

Findings suggesting an adverse event in a neonate or newborn. 